\title{
Syncope after aortic valve surgery
}

\author{
C. Crooijmans · L. M. Rademakers
}

Published online: 11 February 2019

(c) The Author(s) 2019

A 49-year-old man with a bicuspid aortic valve with severe stenosis and moderately depressed left ventricular ejection fraction underwent implantation of a mechanical aortic prosthesis. During the pre-operative evaluation, the electrocardiogram (ECG) showed sinus rhythm with first-degree atrioventricular block and voltage criteria of left ventricular hypertrophy (Fig. 1).

On the fourth postoperative day, the patient complained of sudden onset of rapid palpitations. The ECG is shown in Fig. 2. Both carotid sinus massage and a rapid intravenous bolus of $20 \mathrm{mg}$ adenosine did

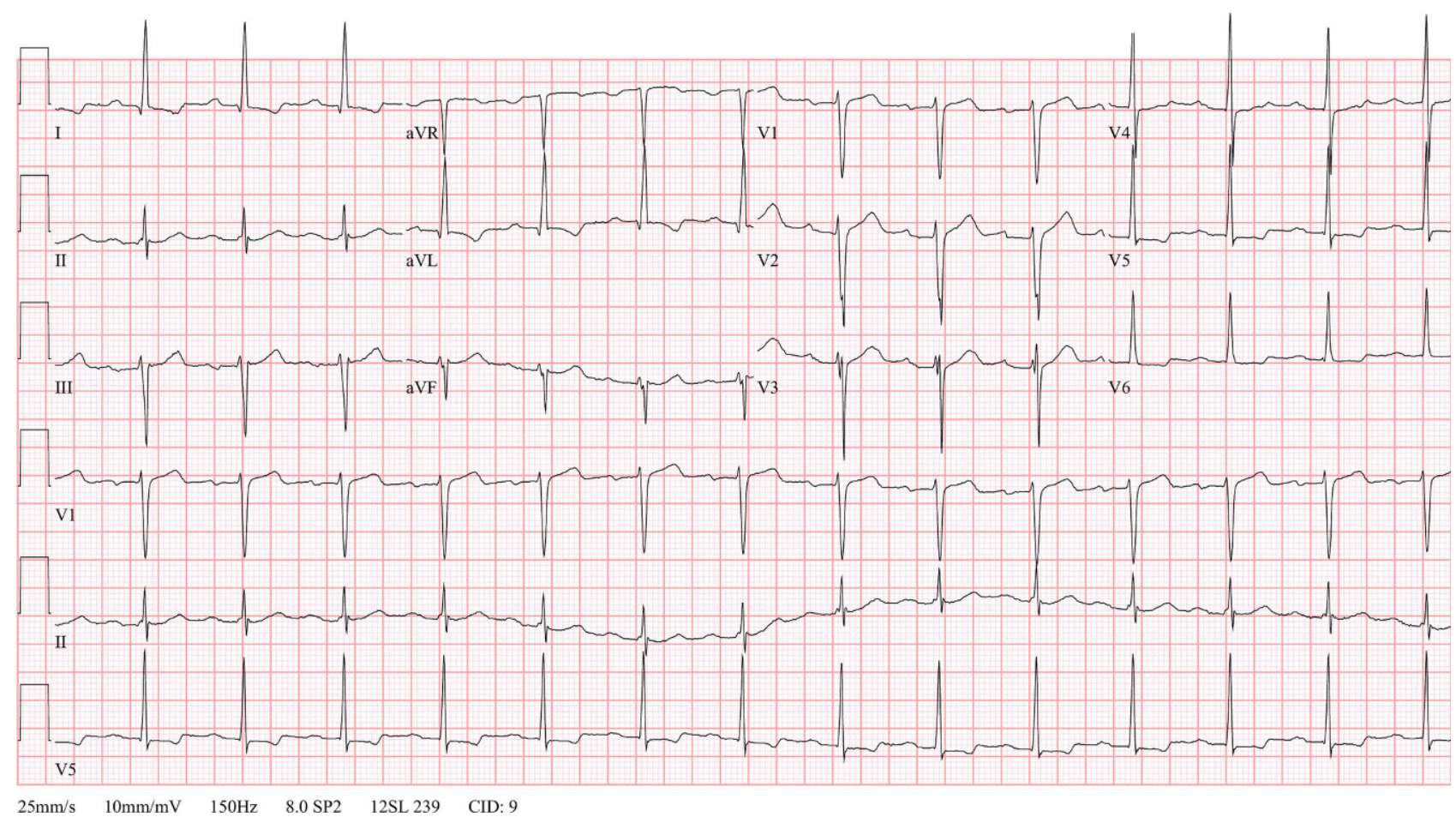

Fig. 1 ECG during pre-operative evaluation 


\section{Rhythm Puzzle - Question}

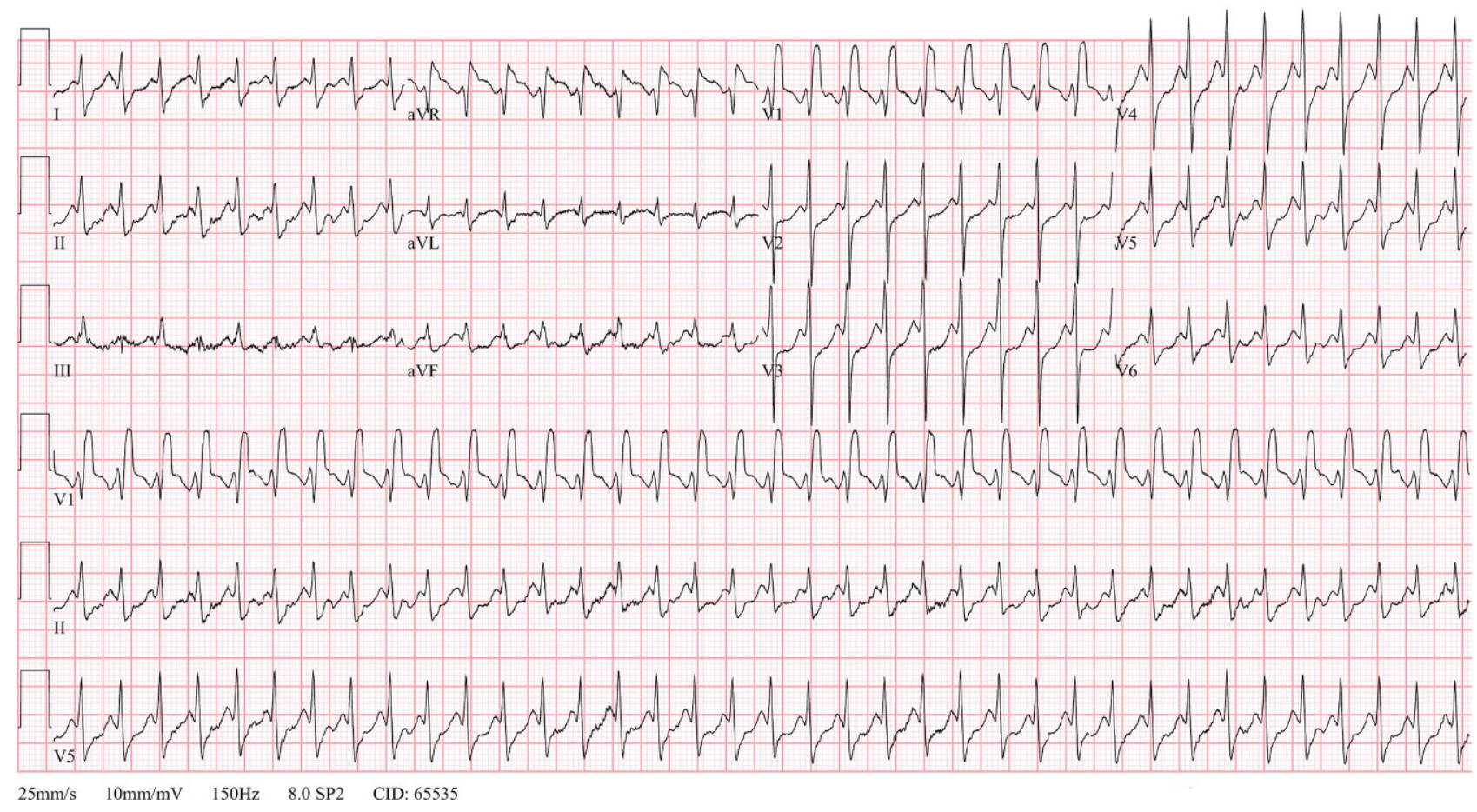

Fig. 2 ECG during rapid palpitations

neither temporarily slow down nor stop the tachycardia. Meanwhile, his blood pressure had declined to $70 / 40 \mathrm{~mm} \mathrm{Hg}$. A few minutes later, the patient lost consciousness and underwent immediate direct-current (DC) cardioversion. What is your diagnosis?

\section{Answer}

You will find the answer elsewhere in this issue.
Open Access This article is distributed under the terms of the Creative Commons Attribution 4.0 International License (http://creativecommons.org/licenses/by/4.0/), which permits unrestricted use, distribution, and reproduction in any medium, provided you give appropriate credit to the original author(s) and the source, provide a link to the Creative Commons license, and indicate if changes were made. 


\title{
Advertisement placed here.
}

\author{
SSS bohn \\ van loghum
}

Houten 2020 


\title{
Advertisement placed here.
}

\author{
SSS bohn \\ van loghum
}

Houten 2020 